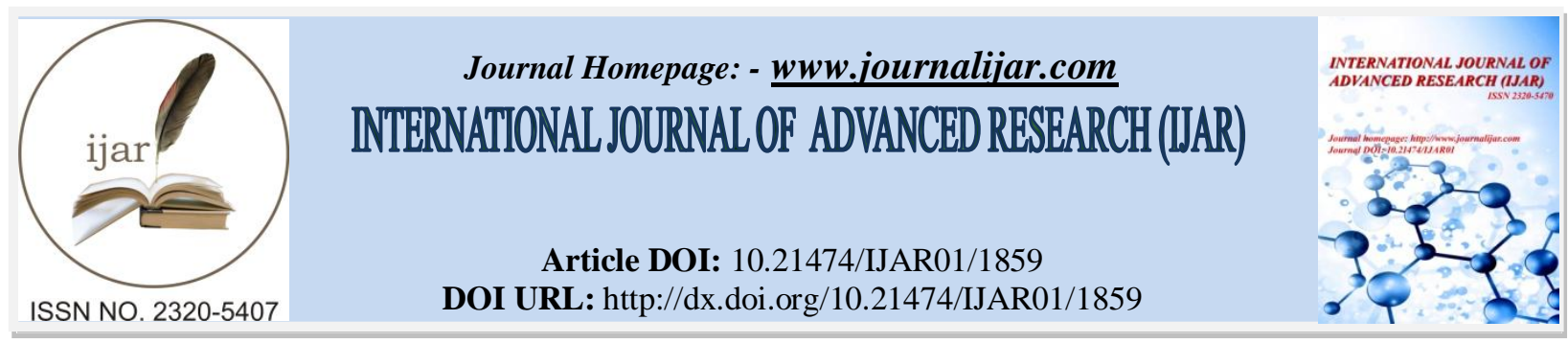

RESEARCH ARTICLE

\title{
DETERRING PLAGIARISM, THE NEED OF THE HOUR: A COMPARATIVE STUDY OF STEPS TAKEN IN HIGHER EDUCATION SYSTEM IN INDIA AND THE UNITED STATES.
}

\author{
Vinod Gupta. \\ Librarian D.A.V Centenary College, Kotkhai Distt.Shimla (H.P) - 171202.
}

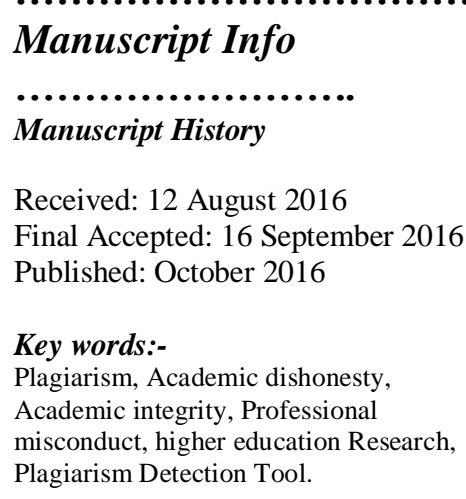

\section{Manuscript Info}

\begin{abstract}
This paper is an attempt to understand the concept of "Plagiarism ", its causes, impacts , detection with reference to comparison in its counter in India and The United States. Plagiarism is defined as an act of academic misconduct or academic dishonesty, where one pretends the other's work/content as his own work without giving due credit to the original author. This activity has brought the Integrity and status of Higher education at stake across the World. Now, it is the need of the hour to curb it and certain steps have been taken in this regard. Higher education policies at national and international level have framed guidelines to deal with this act of academic dishonesty and professional misconduct , so as to safeguard the intellectual property right of the author. Certain Anti -plagiarism Software tools (free online and paid services) are now available to detect it. Provisions of Strict vigilance and severe penalties in the policy codes/guidelines in higher education and its review from time to time are required to curb this menace of Plagiarism in Education World.
\end{abstract}

Copy Right, IJAR, 2016,. All rights reserved.

\section{Introduction:-}

Today we are in $21^{\text {st }}$ century, where the research and development activity has its own importance. Development of Nations is based on these research and development activities being carried out in their respective academic and research institutes. Scholars, researchers, teachers and students enrolled in these institutions have to submit assignment to their parent institutes to complete their Degree Prerequisite. In order to complete these assignments the patrons require additional information that is easily available on internet. The access to open resources on internet and time bound work assignment leads to Plagiarism, deliberately or unintentional.

According to Dic.com." Plagiarism is an act or instance of using or closely imitating the language and thoughts of another author without authorisation and representation of that author's work as one's own, as by not crediting the original author".

A lot of uncertainty has been noticed in defining the plagiarism and how to deal with this problem. Plagiarism could be defined as a breach of journalistic ethic and academic dishonesty or academic fraud. Oxford College of Emory University describes, Plagiarism is the use of "a writers idea or phraseology without giving due credit ".In other words pretending some one's work as their own work without giving due credit to the original author is plagiarism. Some time Plagiarism is confused with Paraphrasing. 'Paraphrasing' means to use other person's idea and putting this idea in your own word, with attributing the ideas to the author and cite the sources in text at the end of the 
sentence. Plagiarism is considered as censored and unlawful activity in the academic and professional world. A question arises in our mind, why Plagiarism occurs ?

Causes of Plagiarism: Certain causes are there, but the exact cause of Plagiarism is ambiguous.

1. Ignorance of knowledge in use of citations by the authors who writes research article.

2. Lack of Skills, required for writing research paper /article such as writing skill, research skill, evaluation skill , understanding of key ideas, using appropriate terminology and language skills.

3. Open access to the information required, is available on internet. Internet is an easy and handy medium to make searches and downloads. One can copy the Ideas/text related to the assignment just by making a click without wasting much time.

4. Time Constraint is also one such reason for plagiarism .Patrons who have to submit their assignments on the last dates are more prone to the Plagiarism as it makes their work easy without making much effort.

5. Social and cultural pressures are often seen on the faces of foreign students. Pressure of getting good grades, fear of failure on foreign world class institutes which are often seen as mark of status in our society. Such pressures encourage plagiarism.

6. Feeling of fearlessness for being caught for Plagiarism is also a reason for plagiarism.

\section{Impact of Plagiarism:- Plagiarism leads to:-}

1. Breach of intellectual property right.

2. Duplication of research.

3. Blot on the name of institution and its patrons.

4. Doubt the credibility of an individual.

5. Unethical behaviour.

6. Serious legal consequences.

\section{Ways to avoid plagiarism:-}

Following are some of the ways to avoid plagiarism.

1. Paraphrase : if one find some relevant information to his work. He should read it and write it in his own words. If he has to use more than two words from the text, he should use quotation marks.

2. Making Citations: One should make citations using proper guidelines.

3. Making Quotations: Quotations should be exactly written in the way it appears and should not be misquoted. Citing a quote can be different from citing paraphrase content .It involves addition of page number or paragraph number in case of web content.

4. Making Citations Of Personal Work: If one uses his own previous research content, he should cite his own work.

5. Making References: one should cite references at the end of his paper. This information is very specific and important and requires proper knowledge of guidelines to cite references.

\section{Checking Plagiarism:-}

In order to check plagiarism or academic dishonesty some mechanism has to be developed .Advancement in software technologies and the internet has provided us with the tools to detect plagiarism. Certain Anti -plagiarism tools are now available free online and some are available as paid software packages.

\section{Free online tools are:-}

1. Anti Plagiarism: this software detects plagiarism and deals with World Wide Web and detects copy pasting content.

2. Paper Rater: it offers three tools such as grammar checking, plagiarism detection and writing suggestions. Available as http://www.paperrater.com/plagiarism-check

3. Duplichecker: it provides analysis within no time.

4. Plagiarisma.net: It has a search box and software for windows. Search for entire URL and files in HTML, Docx, Doc, Txt, Odt and Pdf format $t$ could be made.

5. Plagiarism checker.com: it detects if one has copied from the internet. Available as http:// www.plagiarismchecker.com/

6. Plagium: It detects plagiarism and also alerts the user. Available as http://www.plagium.com/

7. Plagtracker: It detects whether similar text appears on web elsewhere. Available as http://www.plagtacker.com/ 
8. Seesources: it detects plagiarism and takes very less time it checks file in HTML, Docx, doc, Txt format. Available as http://plagscan.com/seesources/

9. Plagiarism-detector: it is software that scans and provides instant report and is designed on the basis of mass storage on internet. Available as http://www.plagiarism-detector.com/

10. Viper Plagiarism scanner: it is a fast tool and scans large number of sources. It requires download and only supports Microsoft windows. Available as http://www.scanmyessay.com/

11. Copyscape : available as http://www.copyscape.com/

12. Paid Software tools are:

1Turnitin: it provides originality check facility, save time, make comments directly on the matter and provide feedback. It supports thirty languages. Available as http://turnitin.com/

2.IThenticate: this also works on the same line as turnitin does.

Both the software use same databases for similarity checks but turnitin has additional database of student paper archives.

3.Plagiarsmdetect: available as http://plagiarismdetect.org/

\section{Policy to deter plagiarism in higher education system in India:-}

In Indian Higher education system, research and development activities are part and parcel of academic curriculum. As a result of these activities Theses and Dissertations are coming out providing a unique and primary source of information. The University Grants Commission (UGC) is the Apex body of Government of India, to control, implement and to monitor the Higher Education structure in India. In India Pursuing M.Phil and Ph.D degree at University level requires submission of Dissertation and Theses respectively, on particular field of study .Upto few years back, these sources do not have open access to the readers and are left unutilised lying on closed shelves in the libraries. Taking note of this underutilisation and to promote open access to these sources across the world, The UGC has notified (Minimum Standards and Procedures for Award of M.Phil/PhD. Degree, Regulation 2009). It states that "it is mandatory for a candidate to submit electronic version of theses and dissertations in Universities and Research Centres .For this digital Repository has to be set up. The task of setting digital repository of Indian Electronic Theses and Dissertations was conferred on INFLIBNET, an IUC centre of UGC, Gandhinagar (Gujarat) with aim to provide access to all Institutions and Universities. 'SHODGANGA 'a Digital Repository of Indian theses and Dissertations was established by INFLIBNET. With the establishment of SHODHGANGA, the need for vigilance on the quality of research, duplication of research and to deal with severe menace of Plagiarism was felt. To check Plagiarism, INFLIBNET after verifying different software decided to procure two software named 'Turnitin' and 'iThenticate'. INFLIBNET centre provide these Plagiarism detection software in 2014.But now in 2015 new Antiplagiarism software 'URKUND'has been adopted by INFLIBNET to check plagiarism. These services were provided to UGC affiliated Universities covered under (section 12B) and are eligible for getting the UGC grants. Application of these software have promoted Universities to detect plagiarism in the work assignments submitted by the students/scholars. The study earlier conducted on use of these two software shows that large number of cases of plagiarism has been detected. Many universities at their own level are also developing new policies to check plagiarism at their own. . However no policy of strict penalties has been framed so far, which is the need of hour.

Policy to deter plagiarism in higher education system in The United States:-

Universities in The United States Of America attracts a large number of students from different parts of the world .Pursuing Higher studies in International Universities/Institutes is considered as a matter of pride in our society .But at the same time it has been seen that foreign students in American Universities/institutes are more prone to this censored activity of academic dishonesty and academic misconduct. According to' Wikipedia ', the students who speaks English as their second language are more prone to commit plagiarism .In The United States Of America, "The Academic Integrity Code ("Code") is set up for American Universities to deal with the menace of academic misconduct .Maintaining academic integrity in American Universities is considered as integral part of their Academic Curriculum and is taken seriously in terms of action taken against plagiarism. A student taking admission to American Universities has to make signed submission in each course to adhere to the "code" in completing his course of study .Violating standards of academic conduct leads to serious issue of disciplinary action. "The Student Conduct Code" prohibits theft and unauthorised use of documents and requires adherence to US local, state and Federal Laws. This code prohibits students to commit censored act of Plagiarism. Violation of this code by repeat offenders could even lead to their suspension or dismissal from the university/institution in combination with other sanctions depending on the nature of offence and circumstantial evidences .In America ,Universities are making use of Plagiarism detection software such as Turnitin, ithenticate, cite master etc. to detect plagiarism 
.University of Verginia has established 'The Plagiarism Resource Centre' that provides' Wcopyfind' software to its departments. This software allows departments and teachers to create database of student's work, which further helps them in comparing their documents. Similarly other Universities in The United States are using different Plagiarism detection tools to deal with this censored act of academic misconduct.

\section{Conclusion:-}

Research and development activity is being carried out across the world and the result of its outcome is available in the form of research article/paper, theses and Dissertations. Students, scholars, researchers busy in their research activities need additional information which is easily available on the internet and are thus more prone to plagiarize, intentional or un

intentional. However many other reasons have been found for occurrence of this misconduct but exact cause is ambiguous. Plagiarism has led to duplication of research, breach of intellectual property right and above all it has brought the Academic integrity at stake. In order to deal with this act of academic fraud various Guidelines and Codes have been framed to check it at national and International level. Availability of Plagiarism Detection tools free online or paid software has eased the work of universities in detecting Plagiarism. The study of plagiarism check policy in India and The United States reveals that Plagiarism is more prevalent in both the countries with Large number of plagiarism cases been detected both way . Both the countries have framed Guidelines/Codes to deal with this act of academic misconduct in Higher education system. But it has been observed that the implementation of "The Academic Integrity Code" and "The Student Conduct Code" in United States are more seriously followed, where violation of this code could lead to serious disciplinary actions, as compared to UGC guidelines in India. Universities in The United states, consider academic integrity as integral part of their Goal. Today Plagiarism is not confined to one or two countries but it has engrossed the entire academic world across the globe. Review of existing policies to handle this act of academic dishonesty at national and international level and seriousness in its implementation is the need of the hour in the Intellectual world.

\section{References:-}

1. Koovakkai, D. (2011). Diagnosing plague: tools and techniques for detecting plagiarism. Retrieved. http://ir.inflibnet.ac.in/handle/1944/1629

2. Harris, Robert A. (2001). The plagiarism handbook: strategies for preventing, detecting and dealing with plagiarism. Los Angles. Pyrczak pub.

3. American University Washington: The Academic Integrity Code. Retrieved on 27 May, 2015. http://www.american.edu>academics>resour

4. Kent state University. Causes of plagiarism. Retrieved on 20, May 2015. http://www2.kent.edu>faculty>plagair

5. www.ugc.ac.in/oldpdf/regulation/mphilphdclarification.pdf

6. Manoj Kumar K. and Arora, Jagdish. Shodhganga and deterring plagiarism in research outputs in Indian Universities $.10^{\text {th }}$ International CALIBRE 2015. Inflibnet, Himachal Pradesh University and IIAS Shimla .March 12-14, 2015.

7. Groak,Mark ..et.al .Term Paper Mill Antiplagiarism Tool and academic integrity .Retrieved on 25 May, 2015. Groak,Mark,et al.-Educause Review. Sep/Oct 2001.40-48. http://www.net.educause/ir/library

8. http://www.thefreedictionary.com.plagirism

9. Wikipedia.http://en.wikipedia.org/wiki/academic-dishonesty\#cite-note-4oct2011

10. Marcus,Jon . Foreign student rule breaking: culture clash or survival skills. The Times Higher Educatio. $6^{\text {th }}$ oct, 2011. . http://timeshighereducation.co.uk/story.asp?sectioncode $=26 \&$ storycode $=417650 \& \mathrm{c}=1$ 